\title{
Free editors and peers: squeezing the lemon dry
}

\author{
Jaime A. Teixeira da Silva \& Vedran Katavić
}

\begin{abstract}
In this opinion piece, some of the practices of academic publication in the biomedical field related to the rewarding, or the lack thereof, of peer reviewers are described and discussed. The role and possibly exploitative relationship of mainstream, established publishers of prestigious journals towards their contributors (authors), and peer reviewers is considered. In addition, the role and accountability of publishers and contributors in "predatory" journals is assessed. Professionals who are recruited by the publishing industry, especially the forprofit industry, either as peer reviewers or editors, to complete a professional task, should be rewarded financially as professionals, as for other sectors of the economy, and not simply exploited for free. Points systems or discounts off a publisher's products do not constitute sufficient, or fair, compensation.
\end{abstract}

Keywords: academic publishing, exploitation, fairness, peer review

\section{State of the Union}

Most academic journals thrive on several key elements: firstly, and most obviously, the submission of (quality) manuscripts, and thus they directly depend on authors; secondly, the quality control imposed by peer review and editorial rigor, and thus the journal's commitment to excellence and academic integrity; thirdly, financial stability and survival, which may be derived from readership or subscription fees. When just one of these core components is amiss, a truly academic journal will surely suffer, and possibly cease publication (Südhof, 2016). Authors, on their part, expect a journal that implements quality control, and are willing to transfer their copyright to ensure (free) publication, even though, once published, their paper might end up behind a pay-wall. Publishers, especially established for-profit commercial publishers, may reap the greatest benefit with the least investment, simply due to their name brand, or the fame of their journals. More often than not, authors flock to such journals, provided that these journals are indexed in prominent indices such as PubMed or Scopus, or carry a journal impact factor, which is widely gamed around the world as a form of compensation for publishing (Callaway, 2016). Publishers thus reap copyrights (nowadays transferred easily through a brief online transfer process) or, where open access (OA) is preferred by authors and their research institutes, publishers may reap highly profitable open access fees.

The diamond OA model, in contrast, offers OA at no cost to authors. Most publishers, academic or not, still rely hugely on the overall goodwill of the academic community, i.e., editors and peer reviewers who still traditionally believe in the honour of serving a journal or a publisher, all in the name of academic endeavour and greater (scientific) good. This free goodwill by academia is increasingly coming under scrutiny, as was recently highlighted in a piece by Times Higher Education (THE, 2016) that highlighted three complaints by two frustrated academics, the first being a complaint that payment for travel and job-related expenses has to be paid up front and reimbursed later, the second a complaint that peer review time is apparently becoming longer and longer at the hands of unpaid peers, and the third being concerns of being underpaid as an external examiner. For-profit publishers, more than any other link in the publishing chain, benefit the most, mainly from freely supplied intellectual services and copyrighted material. Most other professional services in society reward professionals for work they were assigned to, such as agents (i.e., equivalent to 
authors and royalties in this analogy), and reward other professionals for overseeing the work of others, such as consultants (i.e., equivalent to peers and editors and consultancy fees in this analogy).

\section{What happened on the path to the modern peer-review system?}

How then did science reach this state where professionals are exploited by the publishing industry using almost $100 \%$ pro bono work, leading to record profits year upon year , sometimes in billions of US\$ (Larivière, Haustein \& Mongeon, 2015)? This culture of exploitation started when the oldest publishers, which originally represented the work of academic societies and where the publisher represented a safe repository of information, began to exploit the dependence of academics on their services. In exchange for this security, some academics would have felt the need to offer their services and knowledge to further scientific knowledge. Peer review per se developed relatively late as a way of handling the large number of articles the editors could not referee themselves and to answer demands for expert authority and objectivity (due to specializations) (Csiszar, 2016; Spier, 2002). Consequently, exploitation of labour evolved into the norm rather than the exception. How did science reach the point where academics feel so willing to hand over their intellectual contribution on a silver platter, as well as their copyright or money as article processing fees (APFs) - the notion of double intellectual taxation (Teixeira da Silva, 2013a) - and even their time as peers or editors, without being financially compensated? Here, to some extent, a culture of shame has been inculcated (Thérèse \& Martin, 2010) in which those who do not contribute are seen as less academic or non-academic relative to the contributors. Thus, an academic who does not conduct peer review has a negative stigma associated with nonparticipation. How did this exploitative and predatory practice and publishing model evolve and why does it continue to exist and survive today? Evidence shows the willingness of peer reviewers to perpetuate the status quo (Tite \& Schroter, 2007). In fact, the theories to explain our questions are perfectly validated by Elsevier's exploitative model. On August 23, 2016, a Google group member, Stephen M. Fiore, Director of the Cognitive Sciences Laboratory, Institute for Simulation \& Training at the University of Central Florida, revealed an email sent by Elsevier in which a condescending proposal was made in which peers' efforts would be rewarded using a ranking system (The Open Scholarship Initiative, 2016).

In other words, rather than offering a thin sliver of their multi-billion dollar annual profit to financially reward those who offer quality control for their profits, Elsevier prefers to use "gaming theory" to incentivize, and reward, its peer reviewers. The Elsevier email stated that "[T]o encourage efficient and timely reviewing and to recognize the appreciation for the important work of reviewers, Elsevier will publish on the journal's website a list of reviewers with their full names and their relative ranking and percentile in how quickly they submitted their report (computed as days between the invitation to review and the submission of a referee report). Referee anonymity will be preserved because authors are not aware of the dates in which a reviewer was invited and submitted his report. Moreover, Elsevier will not publish the number of days taken for the referee to complete the report, but only the relative ranking and percentile (e.g., a ranking of 120 among 300 reviewers and the 40th percentile). The reviewers' names, ranking, and percentile will be published only for the top $80 \%$ of reviewers in terms of days taken to review. The $20 \%$ of reviewers with the longest review times will not appear in the list." The Elsevier system thus stimulates (unhealthy) competition between academics, not unlike the journal impact factor, and can also lead to new ways of abusing and gaming the system. Moreover, there is no guarantee that peer reviewers are doing a thorough task and may simply be completing a large number of peer reviews to obtain a high "peer ranking."

In reality, since the equation of benefits is imbalanced, the currently widely employed 
science publishing model is exploitative, or predatory. Very few journals recognize the intrinsic and added value that all contributors to the publication process bring, including the authors, reviewers, editors, and even post-publication commentators. Some journals offer a crudely fair system by offering points or discounts for authors, peer reviewers, and editors to publish, peer review or edit, respectively. These points serve as a contribution, recognition or reward. This however, is not equivalent to direct financial compensation for professional services, and may lead to a biased peer review where there is competition to build up points, perhaps at the expense of impoverished peer review. Other journals may offer a discount on the purchase of goods or subscription to the same journal, but again, it is rare to find direct financial compensation. For example, the fast-track fee in the Journal of Medical Internet Research is partly used to compensate peer-review (\$350, non-refundable) (JMIR, 2016). In most cases, however, the "academic" reward or merit lies in being named as a peer reviewer or editor in the journal's formal acknowledgments, i.e., professional services are traded for pride and ego, and altruism gives rise to profit. Do peers and editors feel sufficiently satisfied, compensated for this simple listing, enough to motivate them to continue to fight for quality (control) that, essentially, ensures the profit margin of the publisher? Some peers continue to contribute as peers because they feel academically rewarded and intellectually stimulated, others contribute simply to boost their academic "qualifications" on their resumés, and others yet only contribute as peers because they feel that they may benefit something from serving as a peer, even if to a "predatory" open access journal.

\section{Do attainable or sustainable solutions exist?}

So how do we advance from an archaic exploitative publishing system to a model that is fair, balanced, and more honest? Calls for the overhaul of the peer review system are too numerous to describe here, but recently, Ferreira et al. (Ferreira et al., 2015) suggested that it is time for an "evolutionary" change in the approach to peer review that should, in essence, empower scientists, rather than the "organizations with vested interests in maintaining the current system". The authors propose a three-tiered system of "(i) making peer review mandatory and eventually coupling it with paid reviews; (ii) standardizing the review criteria and guidelines for review by field of expertise; and (iii) creating a Global Peer Review Platform." This rationale is not unlike Elsevier's proposal indicated above. To some extent, the abuse of peers in a false incentivisation game can be avoided by using a Publons-type reviewer rewards system (Publons, 2016), although there are also possible risks associated with Publons that will be discussed separately.

How do we, until this "evolution" overcomes its challenges, fairly compensate, reward, and recognize authors for their intellectual contributions and peer reviewers and editors based on their professional input? Gasparyan et al. (Gasparyan et al., 2015a) offers a possible explanation to this question by recognizing that an increase in the number of sprouting journals has created ethical pressures of finding (and rewarding) well-trained reviewers with expertise, among other factors, in responsible publication practices. With all the inherent limitations of introducing fees, such as creating an offer difficult to refuse, namely financial incentives for doing a timely, but ultimately subpar peer-review (Garg, 2015; Gasparyan et al., 2015b) and publication (and other) privileges (discussed in Nature Editorial, 2014; Corneliussen, 2015; Ferreira et al., 2015; Garg, 2015; Gasparyan et al., 2015a; 2015b), the question remains whether established journals would want to opt for these interim and constructive steps that are partly dictated by, as yet, non-existent peer-review market forces. Those market forces may emerge once a large enough pool of highly sought-after expert reviewers has been created and the reviewers themselves start to dictate their own (business) terms.

To avoid review fatigue, some publishers are trying to establish new gimmicks and 
methods to incentivize their editors and peer reviewers, including direct monetary incentives, as a way to be consistently productive and timely (Publishopenaccess, 2016). One could interpret this as methods to continue exploiting professionals, and hence squeezing the lemon dry until new, replaceable peer reviewers and editors can be found. In all these cases, peer reviewers and editors should exhibit a minimum level of expertise and professional ethics (Teixeira da Silva, 2013b).

Truly exploitative journals, the so called "predatory" journals (Beall, 2016), and to an even greater extent, hijacked journals (Dadkhah, Maliszewski \& Teixeira da Silva, 2016), particularly in the OA boom (or plague), have little or no true regard for scholarly or academic record, and will likely process and publish any study, with poor or no peer and editorial oversight, for a price, i.e., the APF. Such exploitative paper mills have only profit in mind and there is no or limited intellectual or financial compensation, or benefit, to peers or editors who support such practices. Despite this, one sees editor boards of such journals filled with academics, sometimes highly reputable ones, and it makes one wonder why such individuals would be drawn to supporting academically suspect journals. These journals that abuse the peer reviewer pool for non-academic purposes ultimately drain already thinned human resources, instilling a greater sense of being professionally abused. Commercial exploitation by established journals and academic exploitation by predatory and hijacked journals may lead to a state of "burn-out" in which the peer pool may eventually begin to refuse to conduct peer review, in a form of protest, or boycott. Boycotting publishers by researchers (in their roles as authors, reviewers, and editors), libraries, and universities is a fact (e.g., the Elsevier boycott: The Cost of Knowledge, 2016), even if through active avoidance (Schekman, 2013), and are actions and attitudes that definitely may affect a publisher's business model. The wider risk that may emerge from a boycott (or overburdening) by the elite of academia is that senior scientists with profound knowledge of a topic and long-term experience may start to be replaced by junior scientists, who have limited academic or publishing credentials or experience. Consequently, the level of peer review drops, and the confidence in the accuracy of the published literature decreases, as it was academically vetted by amateurs or underqualified individuals.

Thus the current publishing model is in somewhat of a crisis, also because science and scientists are under increasing strain (Belluz, Plumer \& Resnick, 2016). On the one hand, prominent and highly scholarly journals with boastful impact factors, strong metrics, and powerful indexing need not place effort into being exploitative: the community is drawn to "serve" these journals for something as intangible as "prestige", knowing that they will reap a reputation for having served on the boards or as reviewers of such reputable journals, even if they do so for free. In a modern society, the publishing industry is one of the most exploitative and subservient models. What is most surprising is that this model is firmly entrenched in this spectrum of peer reviewed journals, as well as in the psyche of the scientific community. At the polar opposite end we have intellectually and financially predatory journals that parasitize intellectual rights for free and offer no tangible benefits, including quality control by peers or editors, or only superficial oversight. Authors who publish there may be willing to pay APFs for instant gratification, or for padding their resumes using a pay-to-publish basis. However, down the road, such oversight will surely bite authors where it hurts the most, namely their own legends, especially since questionable and poorly vetted research is increasingly becoming scrutinized and subjected to corrections and retractions for failing academic standards. In such cases, authors and publishers share the blame but ultimately, authors bear the brunt of the negative consequences.

A possible exception to the rule may be not-for-profit, truly and fully OA journals that subscribe to the "diamond" OA model or are published exclusively by academic societies, i.e., a movement away from commercial publishers. One example is the Croatian Medical Journal 
(a niche journal owned by four Croatian Medical Schools, and an official journal of several professional societies, academies, and fora, financially supported by the Croatian Ministry of Science, Education, and Sports), which does not charge APFs from authors or charge for access to papers once published (CMJ, 2016), i.e. "free to publish and free to read", i.e., a truly free OA. If all the stakeholders are aware of the pro bono and fair-to-all aspects of the entire scientific publishing enterprise, this may reinforce their positive attitudes toward authorship, editorship, and reviewership. The financial pressures that this "diamond" OA model creates for publishers/owners is not trivial, but it makes this initiative more laudable, if unworkable/unrealistic on a global scale. Another example of a "diamond" OA model is eLife (eLife, 2016). However, these diamond models require committed funders and financial backers, each with their own (hidden) agendas. A more realistic model might be a new option in the "gold" OA models (Open Access Directory, 2016), in which profits are (proportionally) divided among all stakeholders. The added value would be that such fiduciary, logistic, and ethical pressures may help the continued reinvention of the journals' (owners', authors', peerreviewers', and editors') missions to serve their members, academia, and the greater scientific endeavour.

\section{Disclaimer and conflicts of interest}

The authors declare no conflicts of interest. Vedran Katavić served, until 2011, as the Research Integrity Editor in the Croatian Medical Journal.

Jaime A. Teixeira da Silva is currently a retired and independent scientist who obtained his BSc degree in botany and genetics from the University of the Witwatersrand, in South Africa. Following experience with rice and water ecology at the Center for Water in the Environment, Nylsvley, South Africa, working on the genes controlling flower colour and shape in Antirrhinum Majus at the Center of Chemical and Biological Technology, Oeiras, and at the Institute Superior de Agronomia (ISA), in Lisbon, Portugal, serving as greenhouse production manager for Horto do Campo Grande Ltd. / Teleflora Ltd., Lisbon, Portugal, and organic chemistry and secondary metabolite research related to medicinal and aromatic plants at Lisbon University's Faculty of Science, an MSc was obtained in Horticulture from Kagawa University and a $\mathrm{PhD}$ in Agricultural Biotechnology from the United Graduate School of Agricultural Sciences, Ehime University, both in Japan. Global Science Books Ltd. was established in Isleworth, UK, where he served as EIC from 2005-2013.

Vedran Katavić - received his PhD at the University of Zagreb, School of Medicine in 2001, where he is an Associate Professor of Human Anatomy. He teaches anatomy and clinical anatomy, bone biology, and graduate and postgraduate courses on Responsible Conduct of Research (RCR). He served as the Research Integrity Editor in the Croatian Medical Journal (2001-2011), and was the president of the Croatian National Committee for Ethics in Science and Higher Education (2006-2010).

\section{Corresponding author:}

Jaime A. Teixeira da Silva, P. O. Box 7, Miki-cho post office, Ikenobe 3011-2, Kagawa-ken, 761-0799 (Japan)

Email: jaimetex@yahoo.com 


\section{References}

ARNS, M. (2014): Open access is tiring out peer reviewers. In: Nature, 515(7528), p. 467.

BEALL, J. (2016): Predatory journals: ban predators from the scientific record. In: Nature, 534(7607), p. 326.

BELLUZ, J., PLUMER, B. \& RESNICK, B. (2016): The 7 biggest problems facing science, according to 270 scientists. [online] [Retrieved September 27, 2016] Available at: http://www.vox.com/2016/7/14/12016710/science-challeges-research-funding-peer-reviewprocess

CALLAWAY, E. (2016): Beat it, impact factor! Publishing elite turns against controversial metric. In: Nature, 535(7611), pp. 210-211.

CMJ (Croatian Medical Journal) (2016): About Journal. [online] [Retrieved September 27, 2016] Available at: http://cmj.hr/default.aspx?id=26

CORNELIUSSEN, S.T. (2015): Should journals pay peer reviewers $\$ 50$ per hour? In: Physics Today. [online] [Retrieved September 27, 2016] Available at: http://scitation.aip.org/ content/aip/magazine/physicstoday/news/10.1063/PT.5.8092

CSISZAR, A. (2016): Troubled form the start. In: Nature, 532(7599), pp. 306-308.

DADKHAH, M., MALISZEWSKI, T. \& TEIXEIRA da SILVA, J. A. (2016): Hijacked journals, hijacked web-sites, journal phishing, misleading metrics and predatory publishing: actual and potential threats to academic integrity and publishing ethics. In: Forensic Science, Medicine, and Pathology, 12(3), pp. 353-362.

eLIFE (2016): About. [online] [Retrieved September 27, 2016] Available at: https://elifesciences.org/about

FERREIRA, C., BASTILLE-ROUSSEAU, G., BENNETT, A. M., ELlinGTON, E. H., TERWISSEN, C., AUSTIN, C., BORLESTEAN, A., BOUDREAU, M. R., CHAN, K., FORSYTHE, A., HOSSIE, T. J., LANDOLT, K., LONGHI, J., OTIS, J.-A., PEERS, M. J. L., RAE, J., SEGUIN, J., WATT, C., WEHTJE, M. \& MURRAY, D. L. (2016): The evolution of peer review as a basis for scientific publication: directional selection towards a robust discipline? In: Biological Reviews, 91(3), pp. 597-610.

GARG, P.K. (2015): Financial incentives to reviewers: double-edged sword. In: Journal of Korean Medical Science, 30(6), pp. 832-833.

GASPARYAN, A. Y., GERASIMOV, A. N., VORONOV, A. A. \& KITAS, G. D. (2015a): Rewarding peer reviewers: maintaining the integrity of science communication. In: Journal of Korean Medical Science, 30(4), pp. 360-364.

GASPARYAN, A. Y., GERASIMOV, A. N., VORONOV, A. A. \& KITAS, G. D. (2015b): Combined rewarding mechanisms can be implemented to incentivize the best reviewers. In: Journal of Korean Medical Science, 30(6), pp. 832-833.

JMIR (Journal of Medical Internet Research) (2016): Instructions for authors of JMIR. [online] [Retrieved September 27, 2016] Available at: http://www.jmir.org/content/author-instructions\#Fast-track

LARIVIÈRE, V., HAUSTEIN, S. \& MONGEON, P. (2015): The oligopoly of academic publishers in the digital era. In: PLoS ONE, 10(6), e0127502.

NATURE EDITORIAL (2014): Review rewards. In: Nature, 514(7522), p. 274.

OPEN ACCESS DIRECTORY (2016): OA journal business models. [online] [Retrieved September 27, 2016] Available at: http://oad.simmons.edu/oadwiki/OA_journal _business_models

PUBLISHOPENACCESS (2016): Online platforms for recruiting and motivating reviewers. [online] [Retrieved September 27, 2016] Available at: http://publishopenaccess.blogspot.jp/ 2016/01/online-platforms-for-recruiting-and.html

PUBLONS (2016): Reviving Peer Review. Speeding Up Science. [online] [Retrieved September 27, 2016] Available at: http://prw.publons.com/ 
SCHEKMAN, R. (2013): How journals like Nature, Cell and Science are damaging science. [online] [Retrieved September 27, 2016] Available at: https://www.theguardian.com/ commentisfree/2013/dec/09/how-journals-nature-science-cell-damage-science

SCHUKLENK, U. (2015): On peer review. In: Bioethics, 29(2), pp. ii-iii.

SPIER, R. (2002): The history of the peer-review process. In: Trends in Biotechnology, 20(8), pp. 357-358.

SÜDHOF, T.C. (2016): Truth in science publishing: a personal perspective. In: PLoS Biology, 14(8), e1002547.

TEIXEIRA da SILVA, J.A. (2013a): Taxing the intellectual base: should authors foot the publishing bill? In: The Asian and Australasian Journal of Plant Science and Biotechnology, 7(Special Issue 1), pp. 111-113.

TEIXEIRA da SILVA, J.A. (2013b): Responsibilities and rights of authors, peer reviewers, editors and publishers: a status quo inquiry and assessment. In: The Asian and Australasian Journal of Plant Science and Biotechnology, 7(Special Issue 1), pp. 6-15.

THÉRĖSE, S. \& MARTIN, B. (2010): Shame, scientist! Degradation rituals in science. In: Prometheus, 28(2), pp. 97-110.

THE COST OF KNOWLEDGE (2016). [online] [Retrieved September 27, 2016] Available at: http://thecostofknowledge.com/

THE TIMES HIGHER EDUCATION (2016): How long will goodwill in academia last? [online] [Retrieved September 27, 2016] Available at: https://www.timeshighereducation.com /features/how-long-will-goodwill-in-academia-last

THE OPEN SCHOLARSHIP INITIATIVE (2016): Elsevier Awarded U.S. Patent for "Online Peer Review System and Method". [online] [Retrieved September 27, 2016] Available at: https://groups.google.com/forum/\#!msg/osi2016-25/4REh5gD5Zko/4ZVnBrToAQAJ

TITE, L. \& SCHROTER, S. (2007): Why do peer reviewers decline to review? A survey. In: Journal of Epidemiological Community Health, 61(1), pp. 9-12. 